\section{Difficult IUD insertions}

I read Dr Draper's letter ${ }^{1}$ in the January 2008 issue of the Journal with great interest.

May I suggest that another factor may be the increased intensity of counselling these days? This is of course necessary as patients have a right to information and documented counselling is our only defence if complications occur. Nevertheless we need to acknowledge that it increases anxiety for both patient and clinician and this in itself may make fitting harder.

It is matter of national concern that in some areas access to intrauterine device fitting is limited, and we need to encourage the acquisition of a skill that can give a great deal of satisfaction and pride in a service that means a great deal to many of our patients. It would be a shame if medico-legal anxieties took the joy out of performing this and other practical procedures.

Lesley Bacon, FFSRH, MRCGP

Consultant in Sexual and Reproductive Health,

Lewisham Primary Care Trust, London, UK.

E-mail: lesley.bacon@lewishampct.nhs.uk

Reference

Draper IB. Difficult IUD insertions [Letter]. J Fam Plann Reprod Health Care 2008; 34: 67
Reply

I'm sure Dr Bacon in her letter ${ }^{1}$ describes a problem that intrudes into all spheres of clinical practice, not just intrauterine device (IUD) fitting - namely the subtler effects that defensive concerns have on the doctor-patient interaction, frequently with results that are not in the patient's interests. I would agree this is another important factor explaining the phenomenon I described in my original letter ${ }^{2}$ to the Journal, being only too aware of how this has slowly worsened during my 25 or so years of family planning practice.

Considering that a number of experienced practitioners obviously share my concerns about increasingly difficult IUD fitting, would there be any mileage in the Faculty of Sexual and Reproductive Healthcare setting up an advanced IUD certificate that would cover cervical dilatation, local anaesthesia, and so on? The need appears to be out there (we're not all exMRCOG!) and experienced doctors are obviously working out the solutions but how easy is it for the more recently qualified to benefit from the results? More formal organisation of this aspect of training appears appropriate.
Isabel B Draper, MRCGP, FFSRH

General Practitioner, Whitehall Medical

Practice, Rugby, UK.

E-mail:IBD@doctors.org.uk

\section{References}

Bacon L. Difficult IUD insertions [Letter]. J Fam Plann Reprod Health Care 2008; 34: 202.

Draper IB. Difficult IUD insertions [Letter]. J Fam Plann Reprod Health Care 2008; 34: 67

\section{LETTERS TO THE EDITOR}

Letters to the Editor are welcome and generally should not exceed 600 words or cite more than five references. For comments on material published in the most recent issue of the Journal, correspondence should be received within 4 weeks of dispatch of that Journal to be in time for inclusion in the next issue. When submitting letters correspondents should include their job title, a maximum of two qualifications and their address(es). A statement on competing interests should also be submitted for all letters. Letters may be submitted to the Editor or the Journal Editorial Office (details on page 141)

\title{
MEETINGS AND COURSES
}

Annual Courses

Title: MSc/Postgraduate Diploma/ Postgraduate Certificate in Sexual and Reproductive Health Care. Venue: Warwick Medical School, Coventry, UK. Details: See display advertisement on page 204.

\section{Annual Courses}

Title: Courses in Sexual and Reproductive Health organised by General and Sexual Health Solution Events. Details: See display advertisement on page 204

\section{Annual Courses}

Title: Courses in Sexual and Reproductive Health organised by The Margaret Pyke Trust. Details: See display advertisement on the inside back cover.

\section{Annual Courses}

Title: Courses in Sexual and Reproductive Health organised by the University of Liverpool. Details: See display advertisement on the inside back cover.

\section{Academic Year 2008/2009}

Title: Training in Psychosexual Medicine. Venue: Locations throughout the UK. Details: Balint-type seminars for doctors. Basic and advanced level groups with experienced leaders, leading to Diploma and Membership of the IPM. More information available on the IPM website. Accreditation: Accredited training for FSRH Sexual Problems Certificate. Information: Administrative Secretary, Institute of Psychosexual Medicine, 12 Chandos Street, Cavendish Square, London W1G 9DR, UK. Tel: +44 (0) 207580 0631. E-mail: admin@ipm.org.uk. Website: ipm.org.uk.

\section{September 2008}

Title: MSc Sexual Health. Venue: Glasgow Caledonian University, Glasgow, UK. Details: The Masters of Sexual Health programme has been designed to enable a range of professionals to develop critical thinking skills and proactive delivery within the broad context of sexual health It is delivered by e-learning to suit near and distance learners. The programme can be taken part time over 2-5 years. Accreditation: Masters degree. Information: Louise Campbell (Programme Administrator), Nursing, Midwifery and Community Health, Glasgow Caledonian University, Cowcaddens Road, Glasgow G4 0BA UK. Tel: +44 (0) 141331 8646. Fax: +44 (0) 141 331 8312.E-mail: sexualhealth@gcal.ac.uk.

\section{September 2008}

Title: North West Society of Sexual Medicine and Family Planning Autumn Meeting. Venue: Woodlands Conference Centre, Chorley, Lancashire, UK. Details: Morning session: HPV vaccine programme and uptake; management of irregular bleeding with LARC; pharmacy provision of oral contraception. Afternoon session: interactive session on sexual assault. Accreditation: FSRH Information: Mrs Linda Sloan, 5 Redhouse Lane, Eccleston, Chorley, Lancs PR7 5RH, UK. E-mail: lindasloan5@btinternet.com.

\section{October 2008}

Title: Women's Health Concern 19th Annual Symposium on Women's Health. Venue: Royal Society of Medicine, London, UK. Details: A day of interesting and informative lectures given by some eminent professors and consultants on topics including: a new concept in menopausal therapy; HRT and cardiovascular disease; Alerts for Ovarian Cancer; androgen therapy; new management of menorrhagia. Accreditation
FSRH Information: Barbara Halstead, Women's Health Concern, 4-6 Eaton Place, Marlow, Bucks SL7 2QA,UK. Tel: +44 (0) 1628524009 (direct) or +44 (0) 1628478473 (main office). Fax: +44 (0) 1628 482743. E-mail: bhalstead@womens-healthconcern.org. Website: www.womens-healthconcern.org.

\section{9-30 October 2008}

Title: Conference on 'Respect \& Responsibility' and the Launch of the National Clinical Effectiveness Unit of the FSRH organised by Sandyford, Glasgow and the FSRH. Details: See display advertisement on page 203

\section{0-21 November 2008}

Title: Faculty of Sexual and Reproductive Healthcare Current Choices Meeting. Venue: Royal College of Physicians, London, UK. Details: See display advertisement on page 203.

\section{November 2008}

Title: Continuing Education in Reproductive \& Sexual Health Annual Updating Day. Venue: London, UK. Details: One-day Annual Updating Day suitable for all health professionals working in the field of sexual and reproductive health. Accreditation: FSRH applied for. Information: Grace Gray, Training Administrator, Sexual \& Reproductive Health Training Partnership, Southwark PCT, St Giles Road, London SE5 7RN, UK. Tel: +44 (0) 207771 3322. Fax: +44 (0) 20 7771 3338.E-mail: srhtp@southwarkpct.nhs.uk.

24-26 November 2008

Title: Letter of Competence in Medical Education (Loc Med) Residential Course for Potential Instructing Doctors. Venue: London, UK. Details: See display advertisement on page 204.

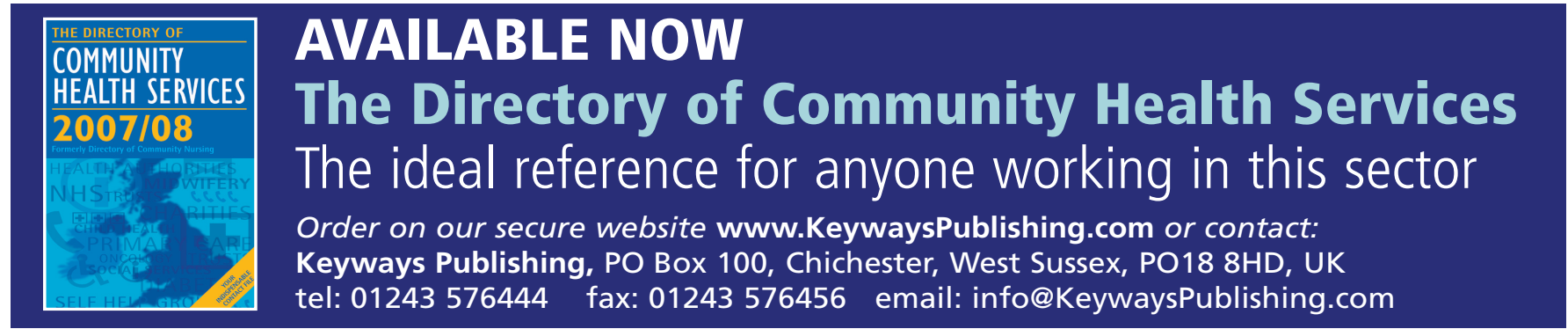

